\title{
Ten Years of Treatment with 400 mg Imatinib per Day in a Case of Advanced Gastrointestinal Stromal Tumor
}

\author{
Silke Cameron ${ }^{\mathrm{a}} \quad$ Inga-Marie Schaefer ${ }^{\mathrm{b}}$ Harald Schwoerer $^{\mathrm{a}}$ \\ Giuliano Ramadori ${ }^{\mathrm{a}}$ \\ Departments of a Gastroenterology and Endocrinology, and \\ ${ }^{b}$ Gastroenteropathology, University Medicine of the Georg August University, \\ Göttingen, Germany
}

\section{Key Words}

Advanced gastrointestinal stromal tumor · Imatinib therapy · Long-term survival · Tolerable side effects

\begin{abstract}
Imatinib mesylate, as treatment for gastrointestinal stromal tumors (GIST), has dramatically changed the prognosis for survival - not only because it is efficacious, but also because it attracted attention to this malignant disease. GIST is now a well-known disease entity and a paradigm for targeted therapies in malignant diseases. A now 74year-old patient presented with recurrence of a primary duodenal GIST (initial diagnosis and primary resection in 1998; diameter $10 \mathrm{~cm}$, KIT exon 11 mutation, PM V559D) and liver metastasis after a second surgical resection was performed in 2000. Conventional chemotherapy with adriamycin and ifosfamide failed to control growth of the relapsed tumor and liver metastasis. In July 2001, compassionate use of imatinib was started. Tumor regression was observed at continuous follow-ups (every 2 months for the first 6 months, and 6 months thereafter) and persisted until now. The patient's physical performance has remained in good condition. Side effects consisted of periorbital edema and sudden muscle cramps of toes and fingers, pain of bones and joints, an intentional tremor, a paler color of the skin, as well as a slight anemia. Imatinib is the first orally administered anticancer drug. Our case shows that a sustained response is possible with continuous therapy over a long time, if the drug is well tolerated. This implies a high compliance of the patient and suggests that resistance to imatinib does not have to develop. Exon 11 (point) mutation might not only represent a positive predictor for imatinib response in general, but especially for imatinib response on long-term.
\end{abstract}

Prof. Dr. med. Giuliano Ramadori 


\section{Introduction}

The gastrointestinal stromal tumor (GIST) is the most common mesenchymal tumor of the gastrointestinal tract. It is a rare (10-20 cases per 1,000,000/year) malignant tumor. GIST develops most frequently in the muscular layer of the gastric wall (60-70\% of the cases) and less frequently in the small ( 30\%) and large intestine (5\%) [1]. The tumor remains asymptomatic for a long time until abdominal pain caused by obstruction of the small intestine, or bleeding occurs due to luminal-ulceration of tumors located in the stomach. It is not uncommon for the tumor to have already metastasized intraperitoneally or into the liver at the time of diagnosis. The therapy consists of surgical resection whenever possible. It has been established that the risk of recurrence may be estimated according to location and size of the tumor as well as the number of mitoses counted in 50 high power fields (HPF) [1]. Tumors with a 'significant' risk of recurrence (after R0 resection) are treated with imatinib as an adjuvant therapy for at least 1 year [2], but patients with high risk of recurrence need such treatment for a longer period $[3,4]$.

Prior to introduction of imatinib, patients with non-operable advanced or metastatic GIST had a median survival of 14-18 months [5]. Introduction of imatinib has increased the median overall survival in patients with advanced GIST to 57 months [6]. Patients with inoperable advanced tumors or with non-resectable recurrent tumors are now treated with imatinib $(400 \mathrm{mg})$ as the first-line therapy with a clinical benefit rate of up to $84 \%$ [5]. This treatment is continued until drug intolerance or initial resistance (2-3 months after starting the therapy) becomes apparent or late resistance occurs.

Follow-up strategies have been suggested [7] but as experience accumulates, they may need to be reconsidered as patients treated with $400 \mathrm{mg}$ imatinib daily can still do well after 9 years of therapy [8].

\section{Case Report}

A 62-year-old man was diagnosed with a necrotic tumor perforating to the descending part of the duodenum. This was determined by endoscopy and by a computed tomography (CT) scan of the abdomen in June 1998 (fig. 1, upper panel). Histopathological examination lead to the diagnosis of a ckit-positive mesenchymal tumor (fig. 1, lower panel) with a maximal diameter of $10 \mathrm{~cm}$ and a proliferation activity of 30 mitoses/50 HPF. Genetic analysis detected an exon 11 mutation (point mutation V559D).

After diagnosis, surgical resection of the primary tumor was performed. However, local relapse and liver metastasis were apparent 18 months thereafter. In February 2000, atypical partial liver resection and tumor reduction of the retroperitoneal tumor mass were performed. Conventional chemotherapy treatment with adriamycin and ifosfamide was started in March 2000 (4 cycles). Although some efficacy of the treatment was detectable by density changes of the tumor within the CT scan (fig. 2), the primary tumor and metastasis continuously increased in size (fig. 3). In July 2001, 2 months after imatinib was approved by the FDA for the treatment of chronic myeloid leukemia in May 2001 [9], and 3 months after the first successful treatment of a patient with metastatic GIST [10], treatment with imatinib 400 mg was started in our patient. Imatinib therapy was started as compassionate use, with the patient having given written informed consent outside of a clinical trial. Continuous reduction of the tumor mass and tumor density was shown by repeated imaging: 3 magnetic resonance tomographies (MRT) and 1 CT scan were performed during the first 6 months of the treatment and every 6 months thereafter. Up to now, $27 \mathrm{CT}$ and $4 \mathrm{MRT}$ scans of the abdomen have been performed. The treatment was well tolerated and has been continued to date. Long-term side effects have included periorbital edema and sudden muscle cramps of the toes and fingers, pain of bones and joints as well as an intentional tremor and a paler skin color, which has to be distinguished from the slight anemia. In 
general, the patient is doing well with a Karnofsky index of $90 \%$. Follow-up checks have been extended, now consisting of alternating CT scan and ultrasonography of the abdomen at 6-month intervals.

\section{Discussion}

Imatinib is the first orally administered anticancer drug able to induce a long-lasting response in a solid malignant tumor. We here present the first case of treatment with imatinib, $400 \mathrm{mg}$ daily, for recurrence of a duodenal GIST, which has now been administered daily for more than 10 years without treatment interruption. This implies a high compliance of the patient, and is in agreement with other observations suggesting that resistance to therapy rarely occurs if it does not develop within the first 2 years of treatment $[8,11]$. As has been reported in the literature [8], GIST patients can be treated for more than 6 years with imatinib safely, without major side effects, if they tolerate imatinib during the first months of the treatment. Once they develop disease progression under imatinib therapy, about $30 \%$ of the patients die within 31 months [11]. Exon 11 mutation might not only represent a positive predictor for imatinib response in general, but especially for the long-term imatinib response [6]. In fact, the vast majority of the long-term survivors in the French BFR14 trial [12], as well as the American B2222 trial [8] had exon 11 mutations. A point mutation, such as in our patient, seems to be more favorable than deletions affecting codons 557 to 558 of the KIT gene [13].

Furthermore, the French group's experience shows that therapy interruption in initially advanced GIST leads to tumor recurrence. Although re-introduction of the therapy is successful in most of the cases [14], some will not respond to the therapy and will possibly die of the disease. This suggests that imatinib therapy, if successful and well tolerated, should be continued in metastasized GIST, even in patients considered having a complete response. Post-imatinib surgery in responders with residual tumors has been discussed but randomized trials are needed before recommendations can be given [15].

Follow-up CT scans for high-risk GIST have been suggested at intervals of 3-4 months for 3 years and every 6 months until 5 years, and yearly afterwards [7]. In cases of sustained response under treatment, such as our case, a reduction of the number of tomographies after 3-5 years might be suggested. As tumor recurrence tends to be intraabdominal, recurrence can also be detected by a specialist performing sonography, although CT scan of the abdomen is still the standard in the follow-up of GIST.

\section{Acknowledgements}

We would like to thank the patient and his wife for allowing us to make public this special experience.

\section{Disclosure Statement}

The authors received support for conferences and travel support i.a. from Novartis. 

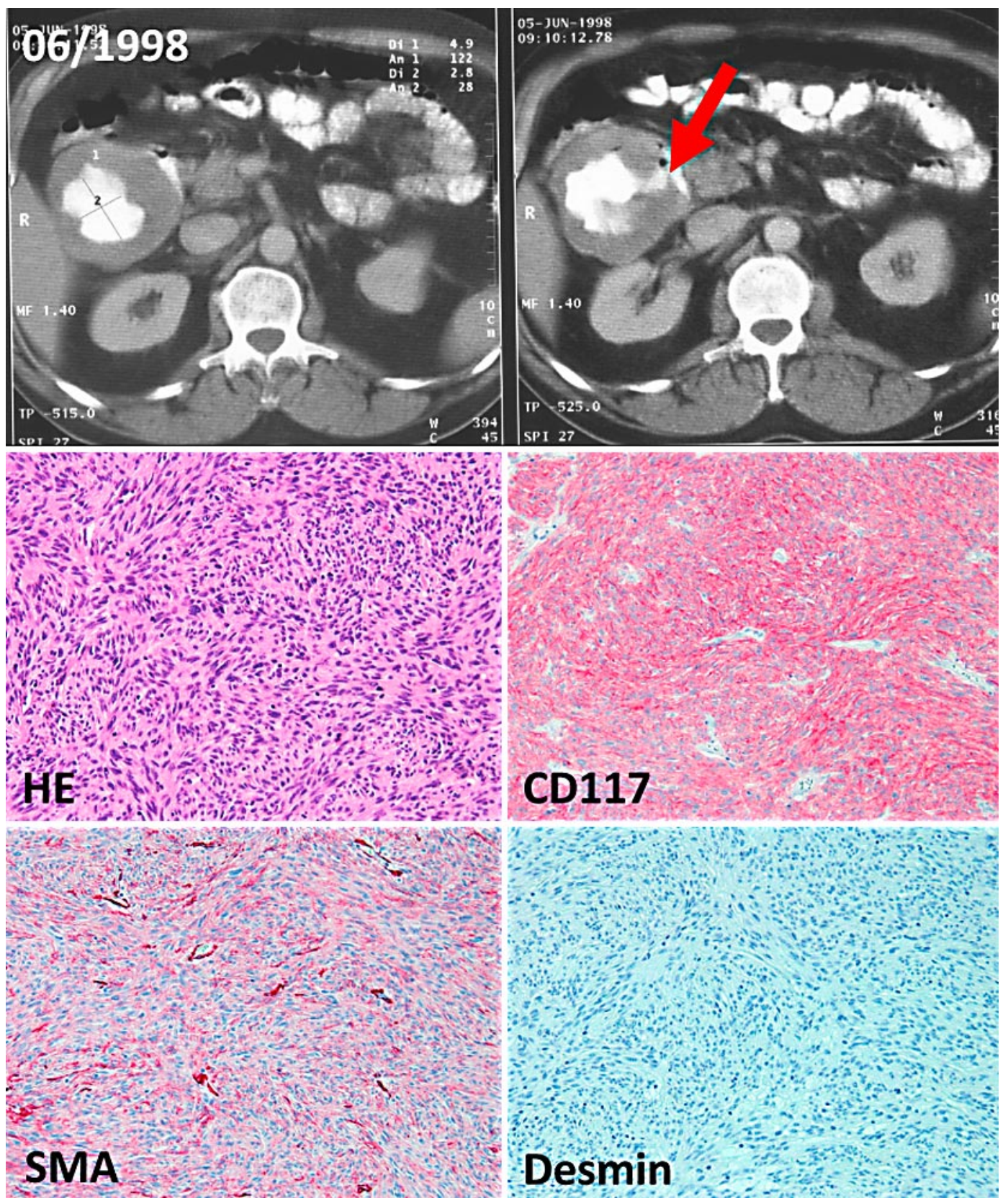

Fig. 1. Upper panel: CT scan of the abdomen showing a cystic abdominal mass. The necrotic tumor of the duodenum is filled with contrast medium, the perforation to the duodenum is indicated with an arrow. Lower panel: Representative paraffin sections of the duodenal GIST (original magnification $200 \times$ ). The sections show a spindle cell (HE staining), ckit-positive (CD117), smooth muscle actin (SMA)-positive and desmin-negative mesenchymal tumor. 

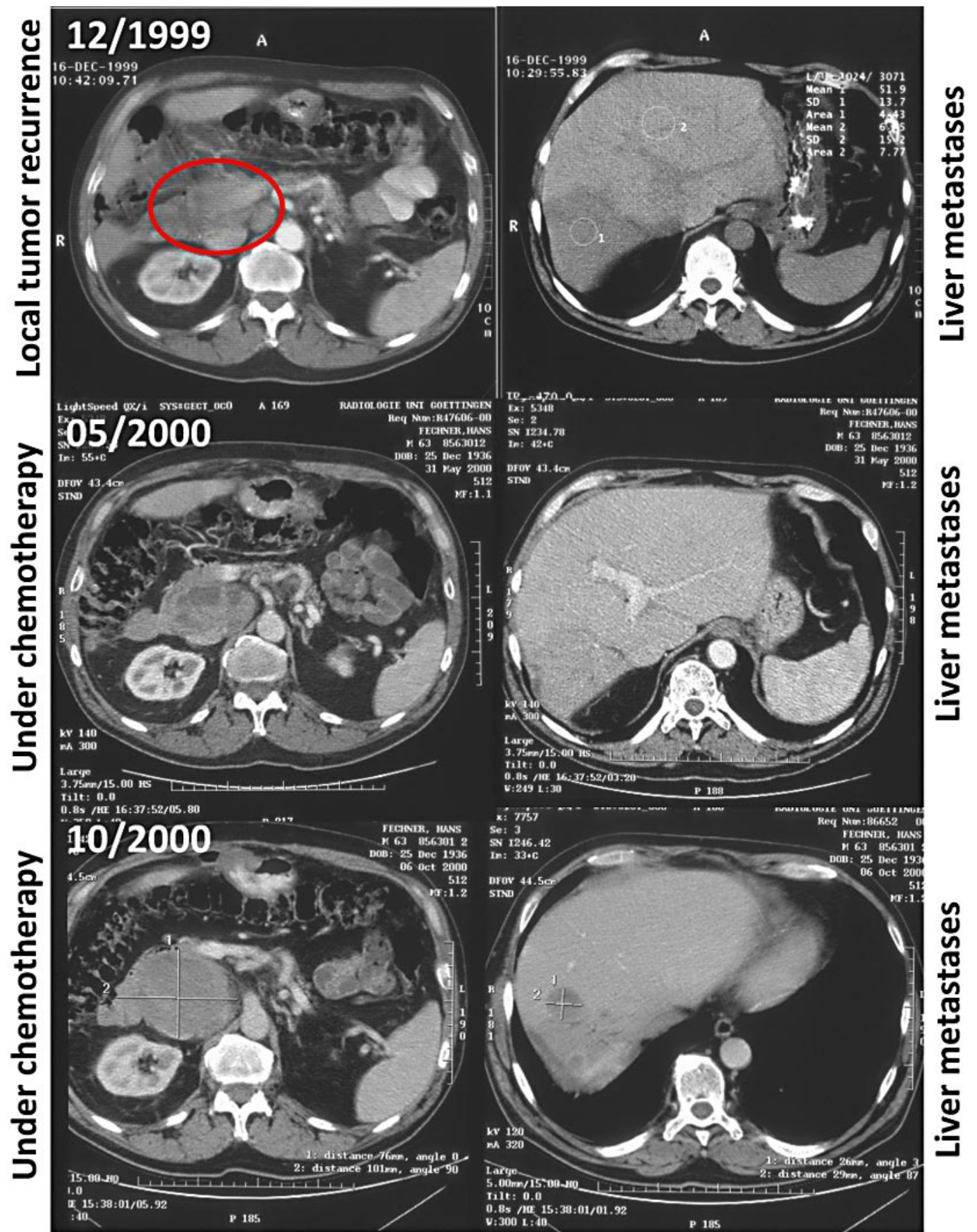

Fig. 2. CT scans of the abdomen at diagnosis of local recurrence (marked with an ellipse) and liver metastasis (upper panel), and after chemotherapy with adriamycin and ifosfamide was started in March 2000 (middle and lower panel). The left-hand side shows the retroperitoneal tumor mass, the right-hand side depicts the liver metastasis. 

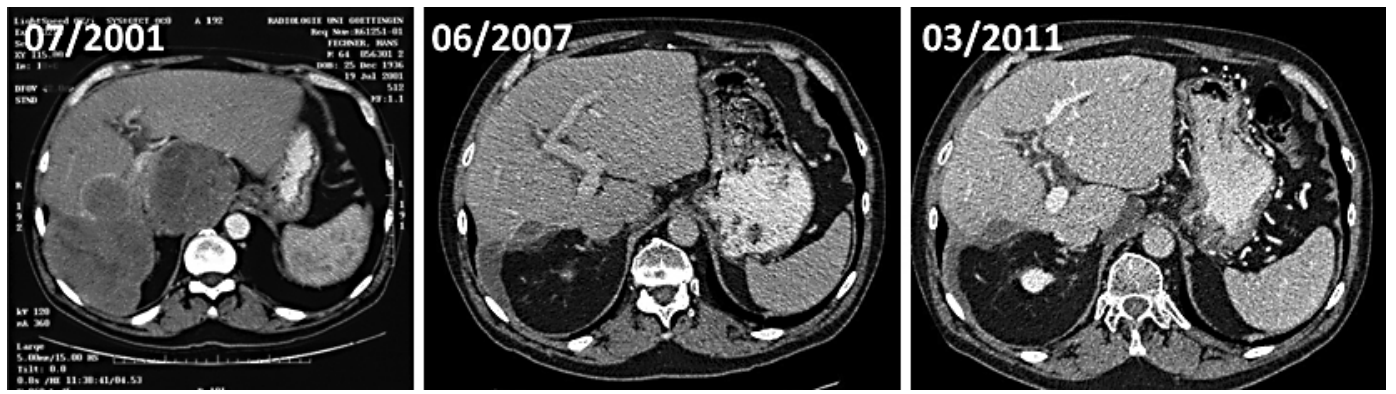

Fig. 3. CT scan of the abdomen showing the retroperitoneal and liver tumor burden before starting imatinib therapy (07/2001) and the residual liver metastasis under continuous therapy with imatinib, performed at different time points (as indicated).

\section{References}

1 Miettinen M, Lasota J: Gastrointestinal stromal tumors: pathology and prognosis at different sites. Semin Diagn Pathol 2006;23:70-83.

-2 DeMatteo RP, Ballman KV, Antonescu CR, Maki RG, Pisters PW, Demetri GD, Blackstein ME, Blanke CD von Mehren M, Brennan MF, Patel S, McCarter MD, Polikoff JA, Tan BR, Owzar K: Adjuvant imatinib mesylate after resection of localised, primary gastrointestinal stromal tumour: a randomised, double-blind, placebo-controlled trial. Lancet 2009;373:1097-1104.

- 3 Blay JY, Le Cesne A, Ray-Coquard I, Bui B, Duffaud F, Delbaldo C, Adenis A, Viens P, Rios M, Bompas E, Cupissol D, Guillemet C, Kerbrat P, Fayette J, Chabaud S, Berthaud P, Perol D: Prospective multicentric randomized phase III study of imatinib in patients with advanced gastrointestinal stromal tumors comparing interruption versus continuation of treatment beyond 1 year: the French Sarcoma Group. J Clin Oncol 2007;25:1107-1113.

4 Joensuu H, Eriksson M, Hartmann J, Sundby Hall K, Schütte J, Reichardt A, Schlemmer M, Wardelmann E, Ramadori G, Al-Batran S, et al: Twelve versus 36 months of adjuvant imatinib (IM) as treatment of operable GIST with a high risk of recurrence: final results of a randomized trial (SSGXVIII/AIO). J Clin Oncol 2011;(suppl)29:abstr LBA1.

5 Desai J: Response assessment in gastrointestinal stromal tumor. Int J Cancer 2011;128:1251-1258.

-6 Blanke CD, Demetri GD, von Mehren M, Heinrich MC, Eisenberg B, Fletcher JA, Corless CL, Fletcher CD, Roberts PJ, Heinz D, Wehre E, Nikolova Z, Joensuu H: Long-term results from a randomized phase II trial of standard- versus higher-dose imatinib mesylate for patients with unresectable or metastatic gastrointestinal stromal tumors expressing KIT. J Clin Oncol 2008;26:620-625.

7 Casali PG, Blay JY: Gastrointestinal stromal tumours: ESMO Clinical Practice Guidelines for diagnosis, treatment and follow-up. Ann Oncol 2010;21(suppl 5):v98-v102.

8 von Mehren M, Heinrich MC, Joensuu H, Blanke CD, Wehrle E, Demetri GD: Follow-up results after 9 years (yrs) of the ongoing, phase II B2222 trial of imatinib mesylate (IM) in patients (pts) with metastatic or unresectable KIT+ gastrointestinal stromal tumors (GIST). J Clin Oncol 2011;(suppl)29:abstr 10016.

-9 Savage DG, Antman KH: Imatinib mesylate - a new oral targeted therapy. N Engl J Med 2002;346:683-693.

10 Joensuu H, Roberts PJ, Sarlomo-Rikala M, Andersson LC, Tervahartiala P, Tuveson D, Silberman S, Capdeville R, Dimitrijevic S, Druker B, Demetri GD: Effect of the tyrosine kinase inhibitor STI571 in a patient with a metastatic gastrointestinal stromal tumor. N Engl J Med 2001;344:1052-1056.

11 Armbrust T, Sobotta M, Gunawan B, Fuzesi L, Langer C, Cameron S, Ramadori G: Does imatinib turn recurrent and/or metastasized gastrointestinal stromal tumors into a chronic disease? - single center experience. Eur J Gastroenterol Hepatol 2009;21:819-823.

12 Blesius A, Cassier PA, Ray-Coquard IL, Italiano A, Adenis A, Rios M, Bertucci F, Huynh TK, Cupissol D, Berge Y, Bompas E, Emile J, Chabaud S, Perol D, Le Cesne A: Who are the long responders to imatinib (IM) in patients with advanced GIST? Results of the BFR14 prospective French Sarcoma Group randomized phase III trial. J Clin Oncol 2011;(suppl)29:abstr 10048. 
13 Martin J, Poveda A, Llombart-Bosch A, Ramos R, Lopez-Guerrero JA, Garcia del Muro J, Maurel J, Calabuig S, Gutierrez A, Gonzalez de Sande JL, Martinez J, De Juan A, Lainez N, Losa F, Alija V, Escudero P, Casado A, Garcia P, Blanco R, Buesa JM: Deletions affecting codons 557-558 of the c-KIT gene indicate a poor prognosis in patients with completely resected gastrointestinal stromal tumors: a study by the Spanish Group for Sarcoma Research (GEIS). J Clin Oncol 2005;23:6190-6198.

14 Le Cesne A, Ray-Coquard IL, Nguyen BB, Adenis A, Rios M, Bertucci F, Duffaud F, Cupissol D, Chevreau C, Bompas E, Cioffi A, Chabaud S, Perol D, Blay J: Time to secondary resistance (TSR) after interruption of imatinib (IM) in advanced GIST: Updated results of the prospective French Sarcoma Group randomized phase III trial on long-term survival. J Clin Oncol 2011;(suppl)29:abstr 10015.

15 Mussi C, Ronellenfitsch U, Jakob J, Tamborini E, Reichardt P, Casali PG, Fiore M, Hohenberger P, Gronchi A: Post-imatinib surgery in advanced/metastatic GIST: is it worthwhile in all patients? Ann Oncol 2010;21:403408. 